Proceedings

\title{
Towards an Empirical Model for the Prediction of the Selectivity of Polymer Membranes ${ }^{\dagger}$
}

\author{
Thorsten Graunke 1,*, Katrin Schmitt 2,3, Sebastian Busch ${ }^{2}$, Stefan Raible ${ }^{1}$ \\ and Jürgen Wöllenstein ${ }^{2,3}$ \\ 1 ams Sensors Germany GmbH, 72770 Reutlingen, Germany; stefan.raible@ams.com \\ 2 Fraunhofer Institute for Physical Measurement Techniques IPM, 79110 Freiburg, Germany; \\ katrin.schmitt@imtek.uni-freiburg.de (K.S.); sebbusch@gmx.de (S.B.); \\ juergen.woellenstein@ipm.fraunhofer.de (J.W.) \\ 3 Department of Microsystems Engineering-IMTEK, University of Freiburg, 79110 Freiburg, Germany \\ * Correspondence: thorsten.graunke@ams.com; Tel.: +49-7121-514-86214 \\ + Presented at the Eurosensors 2018 Conference, Graz, Austria, 9-12 September 2018.
}

Published: 30 November 2018

\begin{abstract}
Polymer membranes are often used in combination with gas sensors for selectivity enhancement, especially with metal-oxide sensors (MOX). We report on the development of an empirical model to predict the gas separation properties of polymer membranes. This model is based on the two parameters sorption and diffusion, represented by the polar fraction of the free surface energy (SFE), and the water absorption combined with the molecule diameter based on Lennard-Jones. We measured the surface tension for a number of common fluoropolymers and used the results to determine their SFE using the graphical method developed by van Oss-ChaudhuryGood, compared them with literature data and further optimized the model. With the optimized model, combined with the information on functional groups in the polymers, we are able to predict the selectivity of polymer membranes.
\end{abstract}

Keywords: polymer membrane; selectivity; gas sensor; separation; model

\section{Introduction}

The reliable detection of toxic and combustible gases is very important in many areas of environmental sensing. In many cases, chemical gas sensors are used for the detection of such gases. These sensors are very sensitive, but often not sufficiently selective. One way to enhance the selectivity of chemical gas sensors is their combination with symmetrical dense polymer filters [1]. It has been observed that polymers having unbalanced charge centers and containing ether groups or halogen atoms have a high selectivity to nonpolar gases such as $\mathrm{H}_{2}, \mathrm{CH}_{4}$ or $\mathrm{CO}$. Therefore, a relationship must exist between the sorption of gases at the interface and the surface energy of the polymers. Also literature data on the water absorption correlate well with the observed separation properties. The lower the water absorption of a membrane, the more specific is its selectivity towards nonpolar substances. All polymers except plastics have both acidic and basic properties.

From this observation, an empirical model was developed that allows predicting the gas separation properties of polymers. The transport of gases through a polymer matrix is primarily defined by the product of sorption and diffusion. The sorption is defined by the polar fraction of the surface free energy (SFE). The sorption of gases to the interface (combination of acid and base) results in a so-called neutralization product (Lewis adduct). As a result, the subsequent diffusion through the polymer membrane is made possible. Yet if we only consider sorption, we neglect diffusion through the polymers. As a measure of the diffusion, the water absorption of the polymers can be 
used. Literature values on the water absorption can often be found in the data sheets of the polymers. The water absorption is correlated with the vacancies in the polymer. If the molecular diameter of a gas component is greater than that of water, the diffusion coefficient decreases, thereby taking into account the dependence on the size of the molecule. The interactions between the gas molecules and the polymer chains are taken into account both through the diffusion coefficient and through the sorption coefficient.

In our study we measured the dispersive and polar fraction of the SFE for a number of common fluoropolymers and used the results to determine their SFE using the graphical method developed by van Oss-Chaudhury-Good. The result is a set of parameters used to predict the gas separation properties of polymers.

\section{Experimental}

\subsection{Gas Permeability Measurement}

The design was realized so that the concentration of a gas in both the feed and permeate can be measured. The gas sensor used was a MOX sensor with a sensitive layer of $\mathrm{SnO}_{2}: \mathrm{Pd}$ mounted on a TO39 socket. The metal cap can be compressed gas-tight with the measuring chamber.

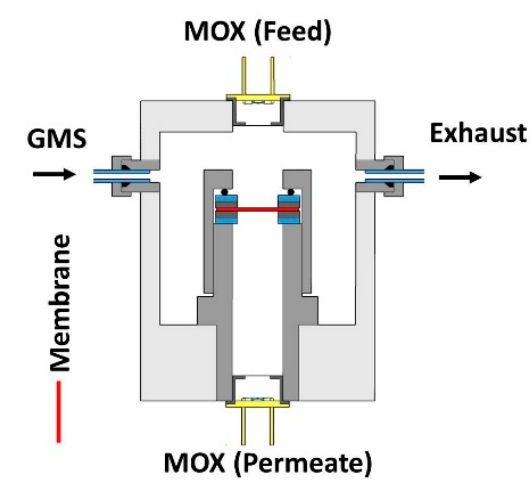

(a)

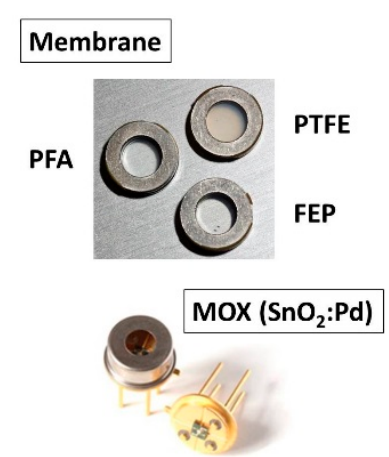

(b)

Figure 1. (a) Sketch of the measuring chamber consisting of two MOX sensors and a holder for inserting polymer filters; (b) Photo of the polymer carriers and the $\mathrm{SnO}_{2}$ :Pd sensors on TO39 socket.

To avoid a damaging of the membrane when installed in the chamber, these were glued in stainless steel discs with a non-degassing epoxy adhesive. Fig. 1 shows a scheme of the measuring chamber and photographs of the polymer carriers and sensors.

\subsection{Contact Angle Measurements}

The results obtained in the determination of the surface free energy (SFE) of polymer surfaces by the method of van Oss, Chaudhury and Good are highly dependent on the choice of the test liquids. For this reason, the dispersive and polar components for the SFE are newly determined for FEP, PFA, PVF and PVDF filters used in this work. The aim of this measurement is to investigate the extent to which literature data can be used to determine the sorption coefficient ks. The test liquids used are water, ethylene glycol and n-hexane. The measurements were implemented with the Drop Shape Analyzer EasyDrop from Krüss. 


\section{Results and Discussion}

\subsection{Gas Permeability of the Fluoropolymers Used}

Fluoropolymers are very suitable for investigating the separation properties. They have a simple structure and the dispersive and polar parts can easily be adjusted via halogen atoms or ether groups [1]. We assumed that nonpolar gases preferentially diffuse through nonpolar membranes such as PTFE. On the other hand, in the case of a polar membrane like PFA, these should be withheld rather.

Yet our investigation of further membranes from the group of fluoropolymers has also shown that the separation properties of these symmetrical dense polymers can not be estimated by simply considering the charge transfer of electrons in the macromolecules, see Table 1.

Table 1. Permeate signals of the MOX sensors combined with PVF, PVDF, PTFE, ETFE, ECTFE, FEP, PFA and Teflon ${ }^{\circledR}$ AF2400 membranes. The given signal ratios $\left(S=R_{0} / R\right)$ are the arithmetic mean of three measurements. The exposure time was $20 \mathrm{~min}$. The values marked in red show filters with a high selectivity to a specific gas.

\begin{tabular}{|c|c|c|c|c|c|c|c|}
\hline Membrane & $\begin{array}{l}\text { MOX } \\
\text { Sensor }\end{array}$ & $\begin{array}{c}\mathrm{H} 2 \\
\left(\mathrm{~S}=\mathrm{R}_{0} / \mathrm{R}\right)\end{array}$ & $\begin{array}{c}\mathrm{CO} \\
\left(\mathrm{S}=\mathrm{R}_{0} / \mathrm{R}\right)\end{array}$ & $\begin{array}{c}\mathrm{CH} 4 \\
\left(\mathrm{~S}=\mathrm{R}_{0} / \mathrm{R}\right)\end{array}$ & $\begin{array}{c}\text { Ethanol } \\
\left(\mathrm{S}=\mathrm{R}_{0} / \mathrm{R}\right)\end{array}$ & $\begin{array}{l}\text { Acetone } \\
\left(\mathrm{S}=\mathrm{R}_{0} / \mathrm{R}\right)\end{array}$ & $\begin{array}{c}\text { Acetaldyde } \\
\left(\mathrm{S}=\mathrm{R}_{0} / \mathrm{R}\right)\end{array}$ \\
\hline PVF & $\mathrm{SnO}_{2}: \mathrm{Pd}$ & - & - & - & - & - & - \\
\hline PVDF & $\mathrm{SnO}_{2}: \mathrm{Pd}$ & - & - & - & 4.2 & 1.1 & - \\
\hline PTFE & $\mathrm{SnO} 2: \mathrm{Pd}$ & 13.9 & - & 1.3 & 24.8 & 44.8 & 1.1 \\
\hline ETFE & $\mathrm{SnO} 2: \mathrm{Pd}$ & 1.4 & - & - & - & - & - \\
\hline ECTFE & $\mathrm{SnO} 2: \mathrm{Pd}$ & 1.4 & - & - & - & - & - \\
\hline FEP & $\mathrm{SnO} 2: \mathrm{Pd}$ & 1.9 & - & - & - & - & - \\
\hline PFA & $\mathrm{SnO} 2: \mathrm{Pd}$ & 3 & - & - & - & - & - \\
\hline $\begin{array}{l}\text { Teflon }^{\circledR} \\
\text { AF2400 }\end{array}$ & $\mathrm{SnO} 2: \mathrm{Pd}$ & 24 & 1.9 & 3.7 & 104.7 & 29.4 & 1.1 \\
\hline
\end{tabular}

The measurements have shown that even highly polar polymers with sufficiently large nonpolar regions in the backbone can be very selective for non-polar gases. The membranes must therefore have a certain bipolarity. The presence of ether groups and inductive regions generated by halogen atoms favor the permeability to non-polar gases.

\subsection{Empirical Model}

The permeability of individual components of a gas mixture through a dense polymer membrane is defined by the respective product of sorption and diffusion:

$$
P_{i}=D_{i} \cdot k_{S}
$$

As shown in the permeation measurements, the sorption of gases is strongly related to the surface interactions. It is therefore obvious to describe the sorption of a gas compound via a donoracceptor interaction. Of interest is therefore the polar part of the surface free energy. The following approach is suggested:

$$
k_{S}=\frac{\left(\gamma^{A B}-\gamma^{+}\right)}{\gamma^{-}}
$$

The value $\gamma^{\mathrm{AB}}$ denotes the polar part, $\gamma^{+}$and $\gamma^{-}$the acid (electron pair acceptor) and base (electron pair donator) part of the SFE. Both the literature values and the measured values of PVF, PVDF, FEP and PFA are summarized in the following table. 
Table 2. Surface energies and other parameters of the fluoropolymers. The sorption coefficient ks was calculated using literature data. The measured values are highlighted in red.

\begin{tabular}{ccccccc}
\hline Membrane & $\begin{array}{c}\text { Total }(\gamma) \\
{[\mathbf{m N} / \mathbf{m}]}\end{array}$ & $\begin{array}{c}\text { Dispersion } \\
\left(\gamma^{\mathbf{L W}}\right)[\mathbf{m N} / \mathbf{m}]\end{array}$ & $\begin{array}{c}\text { Polar }\left(\gamma^{\mathbf{A B}}\right) \\
{[\mathbf{m N} / \mathbf{m}]}\end{array}$ & Acid $\left(\gamma^{+}\right)$ & Base $\left(\gamma^{-}\right)$ & Sorption (k) \\
\hline PVF & $36.7(38.1)$ & $34.8(18.4)$ & $1.9(19.7)$ & $0.2(6.3)$ & $4.5(15.5)$ & $0.38(0.86)[2]$ \\
PVDF & $30.34(27.6)$ & $28.58(18.4)$ & $1.76(9.2)$ & $0.07(1.8)$ & $11.1(12)$ & $0.15(0.61)[3]$ \\
PTFE & 21.5 & 19.6 & 1.9 & 0.3 & 3.2 & $0.50[4]$ \\
ETFE & 18.02 & 17.48 & 0.54 & 0.08 & 0.91 & $0.51[3]$ \\
ECTFE & 30.7 & 29.73 & 0.47 & 0.14 & 0.39 & $0.85[3]$ \\
FEP & $15.14(26.6)$ & $14.96(18.4)$ & $0.18(8.2)$ & $0.09(1.2)$ & $0.09(13.8)$ & $1.00(0.5)[3]$ \\
PFA & $15.43(21.6)$ & $14.96(18.4)$ & $0.47(3.2)$ & $0.19(0.5)$ & $0.29(5.4)$ & $0.96(0.5)[3]$ \\
Teflon ${ }^{\circledR}$ AF2400 & 16.6 & 16.1 & 0.42 & 0.05 & 0.82 & $0.45[5]$ \\
\hline
\end{tabular}

Comparing the sorption coefficient $(\mathrm{ks})$ with the separation properties from Table 1 shows that at values of $\mathrm{kS} \geq 0.6$ preferably non-polar gases such as $\mathrm{H}_{2}, \mathrm{CO}$ or $\mathrm{CH}_{4}$ are transported through the membranes (PFA, ECTFE, FEP). The electrophilic $\left(\gamma^{+}\right)$and nucleophilic regions $\left(\gamma^{-}\right)$in the polar portion of the surface energy $\left(\gamma^{\mathrm{AB}}\right)$ of these membranes are approximately equally pronounced. At values between $>0.3$ and $<0.6$ a high selectivity to acetone and ethanol is observed. If $k s \leq 0.3$, only a permeability to water vapor can be recognized [1]. In these membranes the nucleophilic part $(\gamma-)$ is dominating. In the control measurement (highlighted in red), the order is reversed

$$
\stackrel{\mathrm{H}_{2}, \mathrm{CO}, \mathrm{CH}_{4}}{\widetilde{P F A}}>\overparen{\mathrm{ECTFE}_{2}}>\mathrm{FEP}>\text { ETFE }>\overparen{\text { Acetone }} \underset{\text { PTFE }}{\mathrm{H}_{2}} \stackrel{\text { Ethanol }}{A F 2400>P V D F}>\overparen{\text { PVF }}
$$

Through a pure acid-base approach (sorption), the intrinsic properties of the polymers and thus the diffusion are neglected. It would be conceivable to describe the diffusion of the gas components through the polymer matrix via the water absorption. For the determination of the diffusion coefficient $\mathrm{D}_{\mathrm{i}}$ the following new approach is proposed:

$$
D_{i}=\frac{d_{L j ; H_{2} O} \cdot W A}{d_{L J ; i}}
$$

In Equation (4), dLj describes the Lennard - Jones diameter of the gas component $\mathrm{i}$ and of water. WA is the water absorption of the respective polymer. The WA is correlated with the vacancies in the polymer, the so-called FFV (fractional free volume). If the molecular diameter of a gas component ( $\mathrm{d} \mathrm{L}$, i) is greater than that of water $\left(\mathrm{d}_{\mathrm{L} J}, \mathrm{H} 2 \mathrm{O}\right)$, the diffusion coefficient $\mathrm{D}_{\mathrm{i}}$ decreases, thereby taking into account the dependence on the size of the molecule. The interactions between the gas molecules and the polymer chains are taken into account both via the diffusion coefficient $D_{i}$ and via the sorption coefficient ks.

\section{Conclusions}

It turns out that the use of polymer filters is a promising approach to increase the selectivity of MOX sensors. The empirical method for predicting the selectivity of membranes shows a good agreement with the permeate signals of the MOX sensor when considering fluoropolymer filters. However, the results depend on which parameters are used in the determination of the polar part of the SFE. In addition, further experiments with other polymers should demonstrate how mass transport through non-porous, dense membranes can be more reliably and universally described.

Author Contributions: T.G. conceived and designed the experiments; S.B. and K.S. performed and analyzed the SFE experiments; T.G. performed the gas permeability measurements; T.G and K.S. wrote the paper; S.R. contributed to revising and proofreading of the paper; J.W. proofread the paper and gave valuable suggestions.

Conflicts of Interest: The authors declare no conflict of interest. 


\section{References}

1. Graunke, T.; Schmitt, K.; Raible, S.; Wöllenstein, J. Towards enhanced gas sensor performance with fluoropolymer membranes. Sensors 2016, 16,1605.

2. Lloyd, T.B.; Ferretti, K.E.; Lagow, J. A new approach to chemical characterization of polymer surfaces. J. Appl. Polym. Sci. 1995, 58, 291-296.

3. Lee, S.-W.; Park, J.-S.; Lee, T.R. Analysis of the Wettability of Partially Fluorinated Polymers Reveals the Surprisingly Strong Acid-Base Character of Poly(vinylidene Fluoride). Bull. Korean Chem Soc. 2011, 32, 4148.

4. Schoff, C.K. Painting problem. In Coatings of Polymers and Plastics; Ryntz, R.A., Yaneff, P.V., Eds.; Marcel Dekker: New York, NY, USA, 2003; p. 227

5. Meuler, A.J.; Chhatre, S.S.; Nieves, A.R.; Mabry, J.M.; Cohen, R.E.; McKinley, G.H.; Examination of wettability and surface energy in fluorodecyl POSS/polymer blends. Soft Matter 2011, 7, 10122-10134.

(C) 2018 by the authors. Licensee MDPI, Basel, Switzerland. This article is an open access article distributed under the terms and conditions of the Creative Commons Attribution (CC BY) license (http://creativecommons.org/licenses/by/4.0/). 